\title{
Histopathological Profiles of Rats (Rattus norvegicus) Induced with Streptozotocin and Treated with Aqueous Root Extracts of Ruellia tuberosa L.
}

\author{
Anna Safitri $\mathbb{D}$, ${ }^{1,2}$ Dewi Ratih Tirto Sari $\mathbb{D}^{2,3}$ Bigram Refsilangi, ${ }^{1}$ Anna Roosdiana $\mathbb{D}^{1},{ }^{1}$ \\ and Fatchiyah Fatchiyah $\mathbb{1}^{2,3}$ \\ ${ }^{1}$ Chemistry Department, Brawijaya University, Malang, Indonesia \\ ${ }^{2}$ Research Centre of Natural Genetic Resources (SMONAGENES), Brawijaya University, Malang, Indonesia \\ ${ }^{3}$ Biology Department, Brawijaya University, Malang, Indonesia \\ Correspondence should be addressed to Anna Safitri; a.safitri@ub.ac.id
}

Received 21 June 2021; Revised 15 October 2021; Accepted 26 October 2021; Published 10 November 2021

Academic Editor: Antonio Ortega-Pacheco

Copyright (C) 2021 Anna Safitri et al. This is an open access article distributed under the Creative Commons Attribution License, which permits unrestricted use, distribution, and reproduction in any medium, provided the original work is properly cited.

Diabetes mellitus (DM) is a serious worldwide health threat since the number of people with DM is forecasted to grow annually. Thus, effective and affordable treatment is urgently needed. Our previous studies used $\mathrm{n}$-hexane and hydroethanolic root extracts of Ruellia tuberosa L. which significantly affected diabetic rats. In this study, aqueous $R$. tuberosa L. root extracts were used as treatments for the diabetic rat model and their effects were evaluated. Diabetes was generated by the administration of streptozotocin (STZ) at $20 \mathrm{mg} / \mathrm{kg}$ within 5 sequential days. Male Wistar rats were orally treated with the extracts and standard drug (metformin $200 \mathrm{mg} / \mathrm{kg}$ ) and vehicle every day for 4 weeks. Hypoglycemic effects were assessed for normal, diabetic control, standard, and extract-treated groups. Histopathology was also carried out for the pancreatic, hepatic, and kidney tissues. The progression of diabetes was considerably diminished after extract treatment. In treated rats, the highest dose of extract induced a decline in blood glucose and serum malondialdehyde (MDA) levels at 25\% and 35\%, respectively. Furthermore, aqueous extract of R. tuberosa L. treatment decreased MDA levels in the pancreas by $12 \%$. Histologic examination of the organ tissues of diabetic rats showed deteriorating alterations. After treatment, histopathological damages to the tissues and cells were reversed. The results of the experiments recommend that aqueous extract of $R$. tuberosa L. has antidiabetic effects on STZ-induced diabetic rats; nevertheless, a higher dose of the aqueous extracts is needed to achieve more significant results.

\section{Introduction}

Diabetes mellitus is classified as a metabolic disorder owing to daily-life problems in the 21st century [1]. In the pathophysiology of diabetes, insulin, the hormone that is produced in pancreatic $\beta$-cells, is essential [2]. The occurrence of diabetes has reached epidemic magnitudes and is constantly growing globally. The number of people with diabetes is estimated to be two-fold, from 171 million to 366 million people by 2020 [3]. A comparable trend is seen in Indonesia. Statistics from the Ministry of Health of the Republic of Indonesia affirm that, in 2006, there were just about 8.4 million people in Indonesia who suffered from diabetes [4].
By 2030 , this figure is forecasted to grow to 21.3 million people [4]. Diabetes mellitus management is mostly managed by the administration of insulin and antidiabetic oral drug consumption [5]. Nevertheless, these approaches involve huge budgets and are at risk of causing unpleasant adverse consequences. Because DM treatments are costly, physicians and investigators begin to explore substitute remedies from natural products that are reasonable and have minimum side effects associated with medication using chemical substances.

Exploring bioactive compounds from natural materials can contribute to knowledge in the health sector, both in preventing and treating disease. Indonesia has a very 
abundant diversity of plants that can be utilized to supply raw ingredients for traditional medicine. One of the plants that can be used as a resource of bioactive compounds is from the Acanthaceae family [6]. The genus Ruellia is one of the members of the Acanthaceae family. Ruellia tuberosa L. is broadly spread in Asian countries, i.e., Indonesia [6]. In traditional remedies, this flora is recognized as an antidiuretic, antidiabetic, analgesic, and antihypertensive [7-9].

Based on our previous studies, n-hexane root extracts from $R$. tuberosa L. have activity as an antidiabetic drug in rat diabetic models [10]. These results were shown by blood glucose reduction, MDA level decrease, and kidney histopathological profile recovery [10]. A qualitative test has demonstrated that triterpenoid compounds were present in the n-hexane $R$. tuberosa L. root extracts. Subsequently, an in vivo study of $R$. tuberosa $\mathrm{L}$. hydroethanolic root extracts was conducted and discovered that the extracts had effects on the decrease of blood glucose and MDA levels and affected serum enzyme activity [11-13]. The phytochemical examination carried out in this study found that phytosterol, phenolic, and flavonoid compounds were enclosed in R. tuberosa L. hydroethanolic root extracts [11]. The Fouriertransform infrared (FTIR) spectroscopy and LC-MS (liquid chromatography-mass spectrometry) studies on the kidney histopathological profiles, kidney MDA concentrations, and TNF (tumor necrosis factor) alpha expression of the kidney from diabetic rats after being treated with hydroethanolic root extracts of $R$. tuberosa L. have been reported [14, 15].

Many secondary metabolites, such as flavonoids, and other phenolic compounds commonly dissolve in the polar solvent [16]. Therefore, in this study, a single solvent system, i.e., water, is used to extract the roots of $R$. tuberosa $\mathrm{L}$. The aqueous root extracts of $R$. tuberosa L. are suggested to be benign and efficient which can be used as a natural remedy.

The compounds in the aqueous root extracts of $R$. tuberosa L. were identified and characterized previously [17]. In the antioxidant test using DPPH $(\alpha, \alpha$-diphenyl$\beta$-picrylhydrazyl) free radicals, the aqueous root extracts resulted in an $\mathrm{IC}_{50}$ value of $15.2 \mathrm{mg} / \mathrm{ml}$ [17]. The antidiabetic capacity of the aqueous root extracts was established by performing an in silico study of the extract compounds. Results concluded that the aqueous root extracts of $R$. tuberosa L. have the potential to be used as antidiabetic agents [17]. Considering the biological activities of $R$. tuberosa L. that have been shown previously, it is interesting to evaluate the pharmacological activities of the antidiabetic effect of the aqueous root extracts of $R$. tuberosa L. In this work, the hypoglycemic and histopathological profiles from treatments to diabetic rats using the aqueous root extracts of $R$. tuberosa $L$. are investigated.

\section{Materials and Methods}

2.1. Plant Material. The dried root powder of $R$. tuberosa L. was obtained from Unit Pelaksana Teknis (UPT) or technical operation unit Materia Medica Batu, East Java, Indonesia. The plant was authenticated by a taxonomist from UPT Materia Medica and was accompanied by a letter of confirmation of the species name.
2.2. Total Phenolic and Flavonoid Content of the Extracts. The total phenolic content of the extract was determined using the Folin-Ciocalteu reagent, following the method explained by Singleton and Rossi [18] with some alterations. An aliquot of the sample solution was diluted with water $(4 \mathrm{x})$, and Folin-Ciocalteu reagent was added $(1: 1) .1 \mathrm{~mL}$ of saturated sodium carbonate solution $(8 \% \mathrm{w} / \mathrm{v}$ in water) was added to the solution mixture. The mixture was left at room temperature for $30 \mathrm{~min}$ in a dark condition. The absorbance of the solution was measured at $765 \mathrm{~nm}$ with a UV-Vis spectrophotometer (1601, Shimadzu). Total phenolic content was expressed as gallic acid equivalent $(\mathrm{GAE} / \mathrm{g}$ of sample) based on a standard curve of gallic acid (5-500 mg/ L). All measurements were conducted in triplicates.

Quercetin was used as a reference compound for total flavonoid determination. A quercetin stock solution was formulated by dissolving $5.0 \mathrm{mg}$ of quercetin in $1.0 \mathrm{~mL}$ of methanol; then, a standard solution of quercetin was set by serial dilution using methanol $(5-200 \mu \mathrm{g} / \mathrm{mL})$. An aliquot of quercetin solution or extract solution was individually mixed with $2 \%$ aluminium chloride $(1: 1)$. After stirring together, the solution was set aside at room temperature for $60 \mathrm{~min}$. The absorbance of the reaction mixture was determined at $420 \mathrm{~nm}$ with a UV-Vis spectrophotometer (1601, Shimadzu). The total concentration of flavonoid was calculated from a standard curve and stated as mg quercetin equivalent $(\mathrm{QE}) / \mathrm{g}$. All measurements were conducted in triplicates.

2.3. FTIR Spectroscopic Analysis of Functional Groups of the Extracts. The aqueous extracts of $R$. tuberosa L. were identified as their functional groups using a Fouriertransform infrared resonance (FTIR) spectrometer (1600S, Shimadzu). The measurements were performed at room temperature and recorded from 4000 to $400 \mathrm{~cm}^{-1}$ wavenumber with a spectral resolution of turnover of $4 \mathrm{~cm}^{-1}$. The frequencies of wavenumbers were assigned to the reference literature $[19,20]$ to identify the functional groups that exist in the aqueous root extract of $R$. tuberosa $\mathrm{L}$.

2.4. Diabetes Induction and Treatment. This in vivo study was officially permitted by the Ethics Committee of Brawijaya University with letter no. 1124-KEP-UB. Preparation of the aqueous extracts was previously reported in [17]. Briefly, 20 albino male Wistar rats (7-8 weeks old and body weight 120-180 g) were obtained from the Biosains Institute, Brawijaya University. As soon as the rats arrived, they were adapted to individual confined cages for 1 week with an ambient temperature $\left(22 \pm 3{ }^{\circ} \mathrm{C}\right)$ and light rotation of $12 \mathrm{~h} /$ $12 \mathrm{~h}$ light-dark. The rats were fed with a standard diet and water ad libitum. After the adaptation period, the rats were separated into five groups ( $n=4$ in each group): control (group 1); diabetic (group 2); and diabetic treated with $250 \mathrm{mg} / \mathrm{kg}$ extracts (group 3), $500 \mathrm{mg} / \mathrm{kg}$ extracts (group 4), and $200 \mathrm{mg} / \mathrm{kg}$ metformin (group 5). The extract doses were selected based on the doses used in our previous study [15]. Diabetes mellitus was induced by streptozotocin (STZ) i.p administration with a low dose of $20 \mathrm{mg} / \mathrm{kg}$ for five 
consecutive days. Aqueous extracts and metformin were orally given daily for 4 weeks. The medium-term treatment was applied based on our previous studies on $R$. tuberosa L. on in vivo studies $[10,15]$. Blood glucose levels of overnight-fasted rats were measured every week. In the last week of the experimental time, the rats were fasted for the night; rat organs and blood were harvested for several biochemical examinations.

2.5. Histopathological Examination. After the termination of the experiments, the pancreas, livers, and kidneys were examined for histopathological studies. Histological procedures were based on methods described earlier in [19]. These organs were cut into thin-sectioned pieces $(1 \mathrm{~mm} \times 1 \mathrm{~mm} \times 1 \mathrm{~mm})$. The sections were paraffin-embedded by standard techniques and were stained with haematoxylin and eosin. All organs were then carefully investigated under a microscope (SZX16 Olympus) using $600 \times$ magnification.

2.6. Biochemical Determination. Serum was obtained by centrifugation of the blood samples at $3000 \mathrm{~g}$ for $10 \mathrm{~min}$ in a cold microcentrifuge. Then, MDA concentration in serum was determined following the procedures as in [15] with slight modifications. The MDA concentration was calculated using a QuantiChrom ${ }^{\mathrm{TM}}$ TBARS assay kit. The procedures were conducted according to manufacturer's instructions. A UV-Vis spectrophotometer (Shimadzu UV-visible spectrophotometer UV-1601) was used to detect the intensity of the colour changes at the $530 \mathrm{~nm}$ wavelength on the samples, after the TBA (thiobarbituric acid) reagent was added. The MDA concentration in the pancreas was also determined by a method similar to the abovementioned method. The absorbance values were compared to the MDA levels in the samples.

2.7. Statistical Analysis. Results were stated as mean$\mathrm{s} \pm$ standard error. The statistical package for Social Science (SPSS) version 23.0 for Windows was used for the statistical analyses. The one-way analysis of variance (ANOVA) followed by Tukey's post hoc test was used for the analysis of data. The significant differences were set at $p<0.05$. Histopathological profiles of the organs were analyzed qualitatively.

\section{Results}

3.1. Identification of Aqueous Root Extract of R. tuberosa L. Metabolites Using FTIR. The total phenolic content of the aqueous $R$. tuberosa L. extract was obtained at $3619.231 \pm 0.29 \mathrm{mg}$ GAE$/ \mathrm{L}$ extract. The total flavonoid content of the extract was $1062.121 \pm 0.25 \mathrm{mg}$ QE/L extract. These results show that the aqueous extract of the root contains flavonoids and phenolic compounds.

The infrared spectroscopic study of the FTIR spectra in the midinfrared region $\left(4000-400 \mathrm{~cm}^{-1}\right)$ for the aqueous extract of $R$. tuberosa L. is shown in Figure 1, and characteristic peaks seen in the spectra were numbered 1 to 6. Number 1 to 6 peaks were as follows: $3408.75 \mathrm{~cm}^{-1}$; $2963.22 \mathrm{~cm}^{-1} ; 1588.07 \mathrm{~cm}^{-1} ; 1414.49 \mathrm{~cm}^{-1} ; 1127.11 \mathrm{~cm}^{-1}$; and $1096.25 \mathrm{~cm}^{-1}$. Those peaks were identified as alcohol $\mathrm{O}-\mathrm{H}$ stretching, $\mathrm{C}-\mathrm{H}$ aliphatic, $\mathrm{C}=\mathrm{C}$ aromatics, $\mathrm{C}-\mathrm{C}$ aromatic, $\mathrm{C}-\mathrm{O}$ alcohol, and $\mathrm{C}-\mathrm{H}$ from the aromatic nucleus, for peak numbers 1 to 6 , respectively [20,21]. From these spectrum assignments, the secondary metabolite compounds in the extract were mostly flavonoids or phenolic compounds.

3.2. Hypoglycemic Activity of the Aqueous Root Extract of $R$. tuberosa $L$. The effects of the aqueous root extracts of $R$. tuberosa L. on blood glucose levels of rats are listed in Table 1 . The elevated glucose levels in the diabetic group were discovered to be highly significant, $299.24 \%$ compared to that of the normal group. Blood glucose levels declined after oral administration of the extracts $(250$ and $500 \mathrm{mg} / \mathrm{kg}$ ) or metformin $(200 \mathrm{mg} / \mathrm{kg})$. Nonetheless, diabetes treatments with the aqueous root extracts of $R$. tuberos $a$ L. at the highest dose resulted in a $25.35 \%$ decrease. In the metformin treatment group, the blood glucose declined up to $68.42 \%$.

Another hypoglycemic activity of the aqueous root extracts of $R$. tuberosa L. can be observed from decreases in MDA levels. The results of the MDA concentration measurements are shown in Table 2. In the untreated diabetic group, the MDA concentrations mounted up to $448 \%$ and $216.5 \%$ in the serum and pancreas, respectively. After the treatment, MDA levels in treated groups (groups 3, 4, and 5) decreased significantly (at $p<0.05$ ). The maximum dose used ( $500 \mathrm{mg} / \mathrm{kg}$ body weight) resulted in higher decreases in the MDA levels in the pancreas and serum at $12 \%$ and $34.6 \%$, respectively.

Histopathological profiles from treatments to diabetic rats with the aqueous root extracts of $R$. tuberosa $\mathrm{L}$.

Figure 2(a) shows an islet of Langerhans of Wistar rats in the normal control group. The islet shows a high number of beta cells dispersed all through the islet. In the diabetic group, a fall in the number of beta cells was observed as compared to that in the normal control group rats (Figure 2(b). The degeneration of the beta cells was caused by the streptozotocin used to trigger diabetes. Histopathology of the extract-treated groups shows the partial repair of islets of Langerhans, as shown in Figures 2(c), 2(d), and 2(e). The improvement of necrotic beta cells was remarkably more distinct after treatment with $200 \mathrm{mg} / \mathrm{kg}$ metformin. In untreated diabetic rats, a significant reduction in the diameter of islet cells was observed, as shown in Figure 3. Treatments with $500 \mathrm{mg} / \mathrm{kg}$ aqueous extract have significantly increased the reduction of Langerhans islet diameter. Treatments with $200 \mathrm{mg} / \mathrm{kg}$ metformin have a more significant reduction of the islet cell diameter. A smaller dose of aqueous extract $(250 \mathrm{mg} / \mathrm{kg})$, however, cannot increase the diameter of the islet cells.

Liver segments from the normal control group, as shown in Figure 4(a), revealed normal hepatic features characterized histologically as the numerous hepatocytes with round euchromatic nucleoli and sinusoidal lining. In 


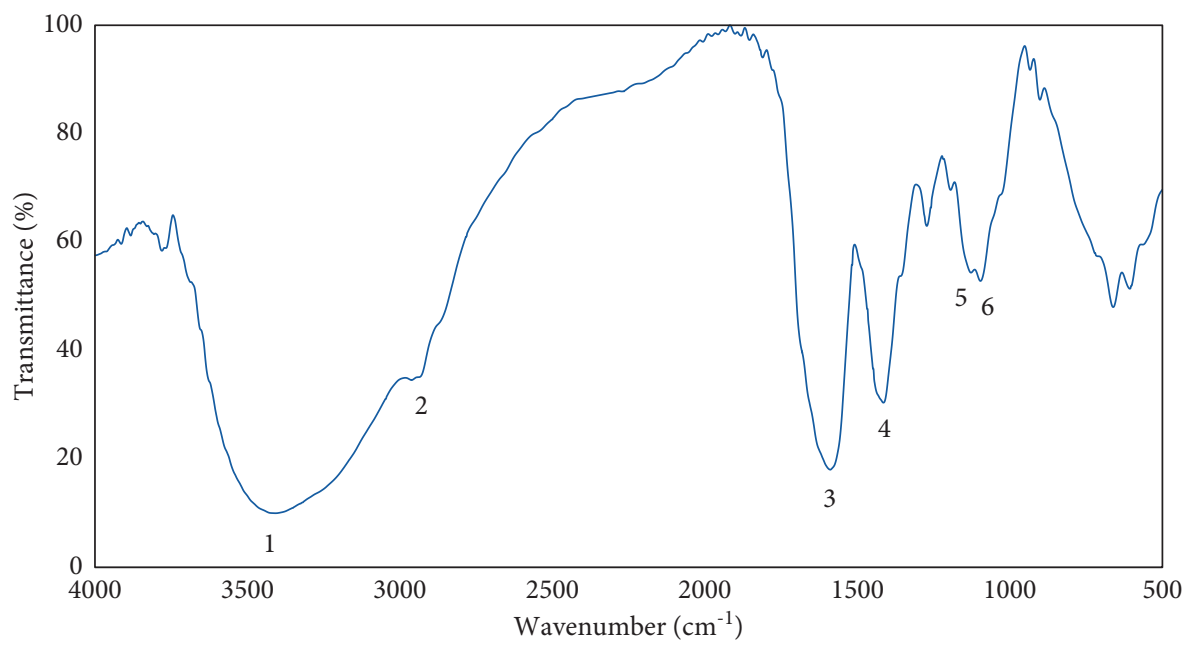

FigURE 1: FTIR spectra of the aqueous root extract of $R$. tuberosa L.

TABLE 1: Blood glucose levels on rats at the end of the treatment, in week 4, in groups 1 to 5 .

\begin{tabular}{lcc}
\hline Group & Blood glucose level $(\mathrm{mg} / \mathrm{dL})^{*}$ & Changes $(\%)$ \\
\hline 1 (normal) & $131.2 \pm 18.12 \mathrm{a}$ \\
2 (diabetic) & $523.8 \pm 17.99 \mathrm{e}$ & 299.24 \\
3 (dose of $250 \mathrm{mg} / \mathrm{kg})$ & $454.6 \pm 12.52 \mathrm{~d}$ & 13.21 \\
4 (dose of $500 \mathrm{mg} / \mathrm{kg})$ & $391.2 \pm 17.44 \mathrm{c}$ & 25.35 \\
5 (metformin $200 \mathrm{mg} / \mathrm{kg})$ & $165.4 \pm 13.55 \mathrm{ab}$ & 68.42 \\
\hline
\end{tabular}

* Different notations indicate significant differences between treatments $(p<0.05)$.

TABle 2: Serum and pancreas MDA levels on rats at the end of the treatment, in week 4, in groups 1 to 5.

\begin{tabular}{|c|c|c|c|c|}
\hline Group & Serum MDA level $(\mu \mathrm{g} / \mathrm{dL}) *$ & Changes & Pancreas MDA level $(\mu \mathrm{g} / \mathrm{dL}) *$ & Changes \\
\hline 1 (normal) & $1.27 \pm 0.18 \mathrm{a}$ & & $0.237 \pm 0.03 a$ & \\
\hline 2 (diabetic) & $6.96 \pm 0.41 \mathrm{e}$ & $448.03 \%$ & $0.75 \pm 0.12 \mathrm{~d}$ & $216.45 \%$ \\
\hline $3($ dose of $250 \mathrm{mg} / \mathrm{kg})$ & $6.04 \pm 0.15 \mathrm{~d}$ & $13.22 \%$ & $0.69 \pm 0.09 \mathrm{~d}$ & $8.0 \%$ \\
\hline $4($ dose of $500 \mathrm{mg} / \mathrm{kg})$ & $4.55 \pm 0.33 c$ & $34.63 \%$ & $0.66 \pm 0.07 c$ & $12.0 \%$ \\
\hline 5 (metformin $200 \mathrm{mg} / \mathrm{kg}$ ) & $2.35 \pm 0.45 b$ & 66.24 & $0.367 \pm 0.03 b$ & $51.07 \%$ \\
\hline
\end{tabular}

* Different notations indicate significant differences between treatments $(p<0.05)$.

Figure 4(b), liver tissues of diabetic rats displayed cellular abnormalities with areas of necrosis, vascular obstruction, and cellular degeneration when compared to the healthy group. The liver tissue of diabetic rats treated with extracts at a dose of $250 \mathrm{mg} / \mathrm{kg}$ indicated a slight area of cellular repair with marked vascular congestion and cellular degeneration as compared with those in the normal and diabetic control groups (Figure 4(c)), whereas in Figure $4(\mathrm{~d})$, diabetic rats treated with extracts at a dose of $500 \mathrm{mg} / \mathrm{kg}$ exhibited moderate areas of cellular restoration, vascular congestion, and nuclei. The metformin group showed some typical healthy features as shown in the normal control rats with other minor degenerative changes (Figure 4(e)). Vacuolization has appeared in all the groups in different degrees, Figure 5. The highest degree was shown in the diabetic group. Treatments with 250 and $500 \mathrm{mg} / \mathrm{kg}$ aqueous extracts attenuated this effect. The percentage was down to $70 \%$ and $50 \%$, respectively. A $200 \mathrm{mg} / \mathrm{kg}$ metformin treatment diminishes this liver damage by $30 \%$.
The renal glomerulus histopathology in the normal rat group (Figure 6(a)) displays the appearance of healthy kidney tissues. These were indicated by the fact that the kidney tubular structures are complete with a clear and considerable lumen and with the glomerulus and Bowmen's capsule shapes around them being clear and undamaged and coordinated with noticeable cell nuclei. Significant alterations took place in the histopathological characteristics of the kidney glomerular and tubular in the diabetic group (Figure 6(b)). The morphologic abrasions of the glomerulus have been shown with the narrowed capsule bowmen structures and glomerular necrosis. There were repair and ameliorations in the histopathological shapes in the rat treated groups, as shown in Figures 6(c), 6(d), and 6(e). Significant improvements were shown in treatment with extracts at the highest dose $(500 \mathrm{mg} / \mathrm{kg})$ and with metformin. Bowman's space and glomerulus sizes were narrowed down, and the tubule epithelium also displayed enhancement. From the calculation, Bowman's space diameter was significantly reduced with treatments of $500 \mathrm{mg} / \mathrm{kg}$ aqueous 


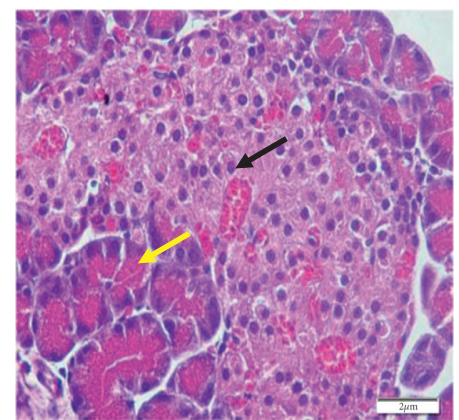

(a)

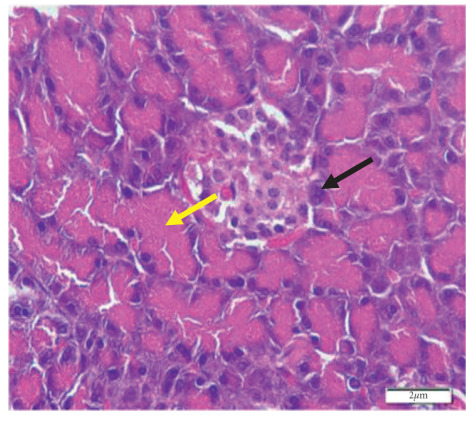

(d)

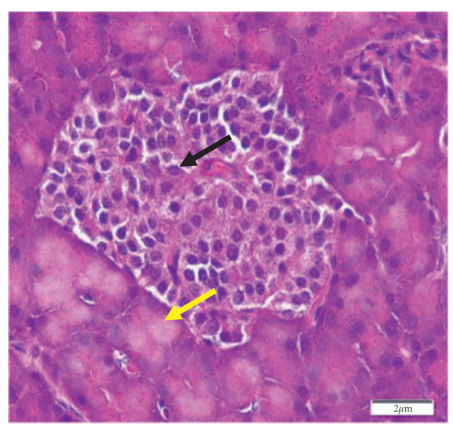

(b)

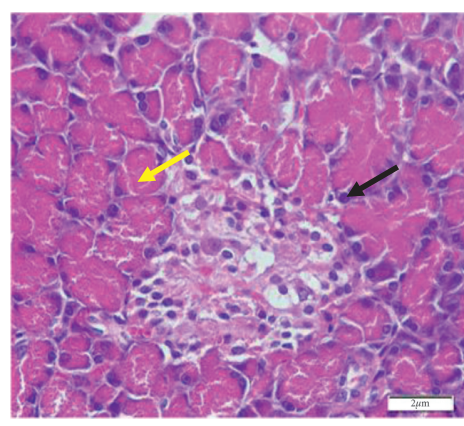

(c)

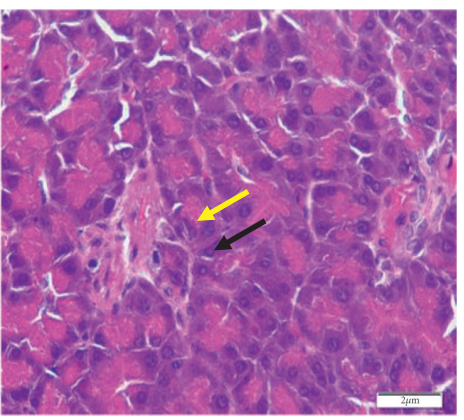

(e)

Figure 2: Histopathology of the pancreas in (a) the normal control group; (b) the diabetic control group; (c) diabetic rats treated with $250 \mathrm{mg} / \mathrm{kg}$ extracts; (d) diabetic rats treated with $500 \mathrm{mg} / \mathrm{kg}$ extracts; and (e) diabetic rats treated with metformin $200 \mathrm{mg} / \mathrm{kg}$, with $600 \times$ magnification. Black arrows show beta cells; yellow arrows show Langerhans islet.

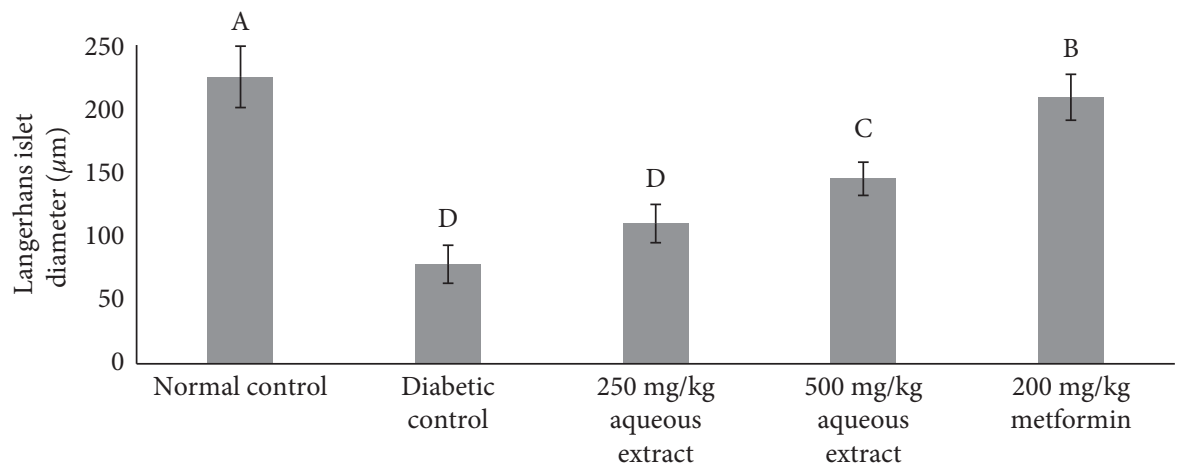

FIgURE 3: Langerhans islet diameters for all groups. Different notations indicate significant differences between treatments $(p<0.05)$.

extracts and $200 \mathrm{mg} / \mathrm{kg}$ metformin, as shown in Figure 7 . Importantly, $500 \mathrm{mg} / \mathrm{kg}$ aqueous extracts had a more significant effect to lower Bowman's space than metformin.

\section{Discussion}

The characterization of the secondary metabolites in the aqueous root extracts of $R$. tuberosa L. led to the detection of flavonoids, phenolics, ascorbic acids, and tannins [17]. Previously, the antioxidant activity of the aqueous root extracts of $R$. tuberosa $\mathrm{L}$. has also been examined and resulted in an $\mathrm{IC}_{50}$ of $15.22 \mathrm{mg} / \mathrm{mL}$ that was considered as high antioxidant capacity [17]. The bioactive compounds present in this plant as shown in the FTIR study may be accountable for the hypoglycemic effect observed in this study. The FTIR spectra from the aqueous root extracts of
R. tuberosa L. indicated the functional groups that existed were mostly phenolic and flavonoid compounds. Based on our previous research using LC-HRMS analysis [17], phenolic and flavonoid compounds were enclosed in the aqueous extract of $R$. tuberosa $\mathrm{L}$.

Phenolic acids and flavonoids have been known in various studies to have high pharmacological and biological activities. These include anti-inflammatory, antioxidant, antibacterial, and antidiabetic activities [22-25]. Therefore, the presence of these phytochemicals was the importance of the study and suggestive of their application in in vivo studies $[16,26]$.

In this current study, we have proved for the first time the antidiabetic activities of aqueous extracts of $R$. tuberosa L. in medium-term treatments (4 weeks) and their prevention of organ complications in STZ-induced diabetic rats. 


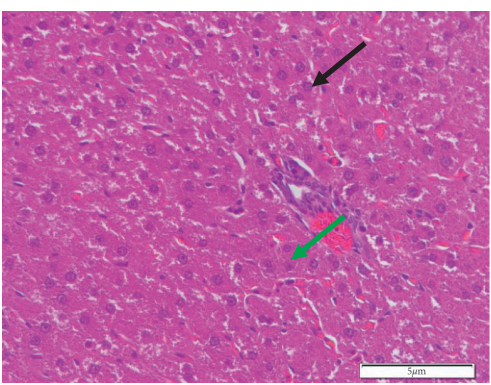

(a)

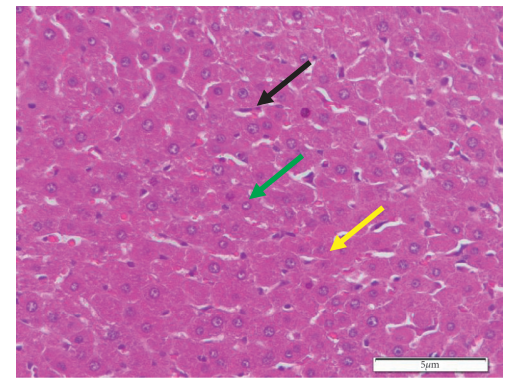

(d)

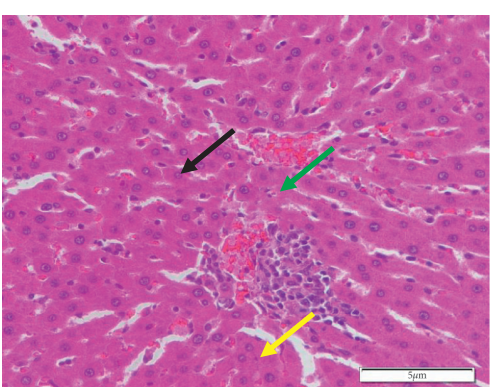

(b)

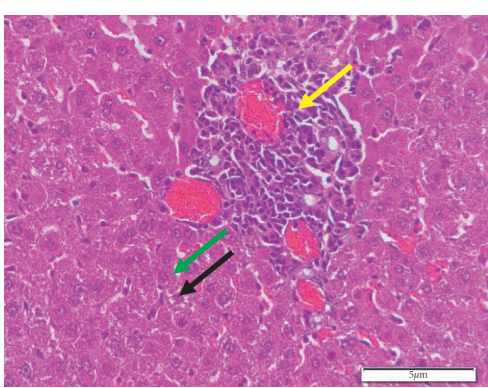

(c)

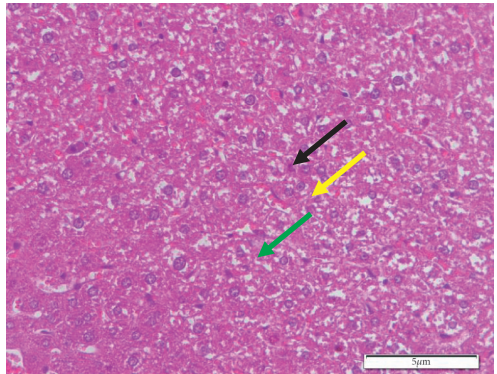

(e)

FIGURE 4: Histopathology of the liver in (a) the normal control group; (b) the diabetic control group; (c) diabetic rats treated with $250 \mathrm{mg} / \mathrm{kg}$ extracts; (d) diabetic rats treated with $500 \mathrm{mg} / \mathrm{kg}$ extracts; and (e) diabetic rats treated with metformin $200 \mathrm{mg} / \mathrm{kg}$, with $600 \times \mathrm{magnification}$. Black arrows show hepatocytes; yellow arrows show vacuolization; and green arrows show the sinusoidal layer.

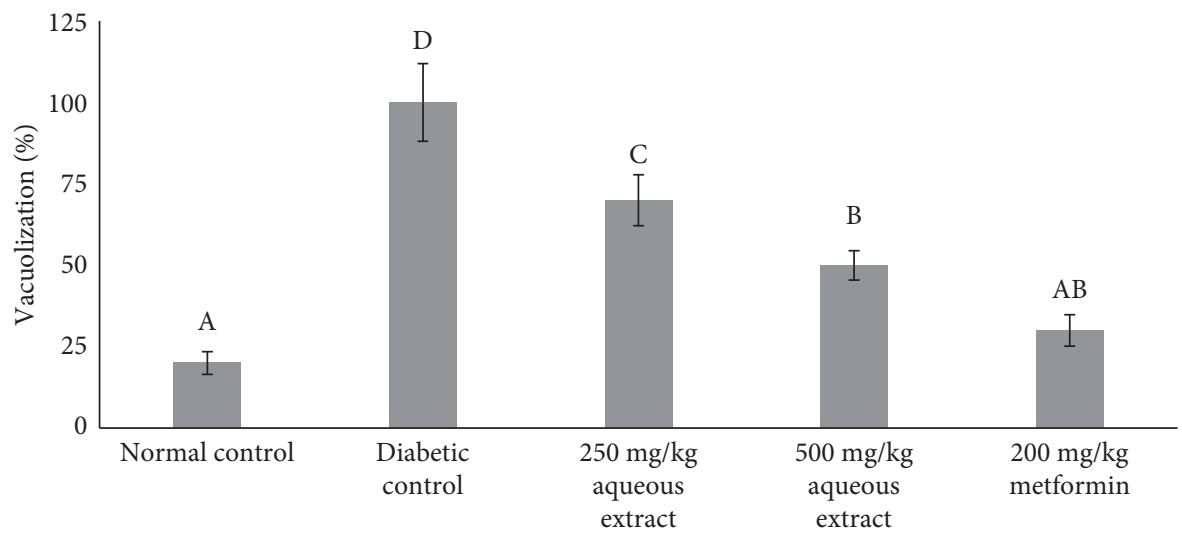

FiguRE 5: Vacuolization or lipid droplets for all groups. Different notations indicate significant differences between treatments $(p<0.05)$.

Our results indicated that the medium-term treatment with 250 and $500 \mathrm{mg} / \mathrm{kg}$ aqueous root extracts of R. tuberosa L. decreased considerably blood glucose in diabetic rats compared with that of untreated diabetic rats, in a doserelated manner. In addition, this treatment had lessened MDA concentrations in diabetic rats compared with those of untreated ones, also in a dose-proportional manner. This hypoglycemic activity relates to the presence of the beneficial compounds contained in the extracts, including betaine, daidzein, hispidulin, and 4-coumaric acid [17].

Daidzein and hispidulin are classified as flavonoid compounds, while 4-coumaric acid is a phenolic compound. Both phenolic and flavonoids have been suggested to have high antioxidant activity [27]. Hispidulin can act as an antidiabetic compound via stimulation of GLP-1 secretion and suppression of hepatic glucose production [27].
Daidzein has been evaluated to have an antidiabetic activity from clinical, preclinical, and cell culture studies [28, 29]. Betaine, an oxidation product of choline, is an organic osmolyte that can protect cells from oxidative stress [30].

However, the hypoglycemic activity shown from the decrease in blood glucose and MDA pancreatic and serum concentration was not as high as when diabetic rats were treated with $\mathrm{n}$-hexane [10] or hydroalcoholic root extracts [11] of $R$. tuberosa L. Furthermore, blood glucose levels in the treatment rat groups (groups 3 and 4) did not return to normal levels as in the healthy rats (group 1).

This suggests some possible explanations. Firstly, water used as a single solvent system cannot extract all secondary metabolites contained in the root of $R$. tuberosa L. Another thing is that slight decreases in blood glucose and MDA levels in the serum or rat's pancreas were due to a very large 


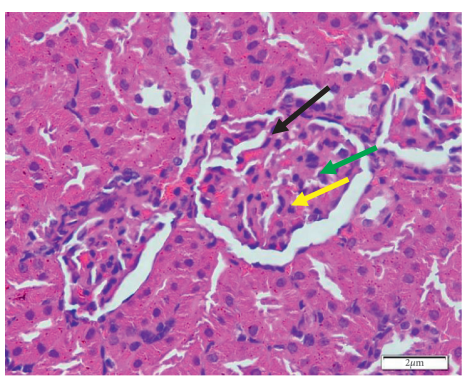

(a)

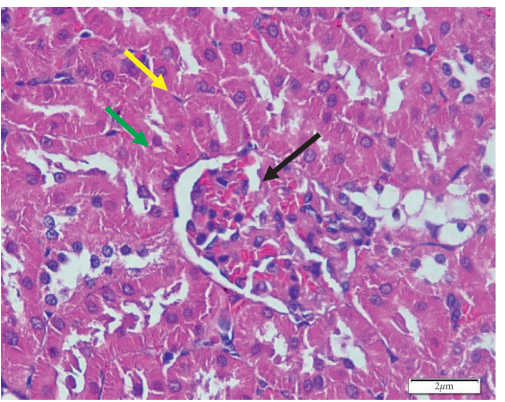

(d)

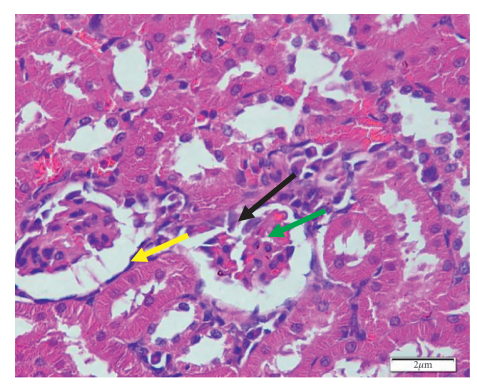

(b)

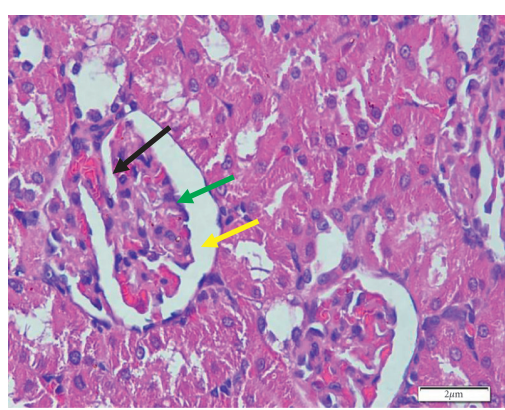

(c)

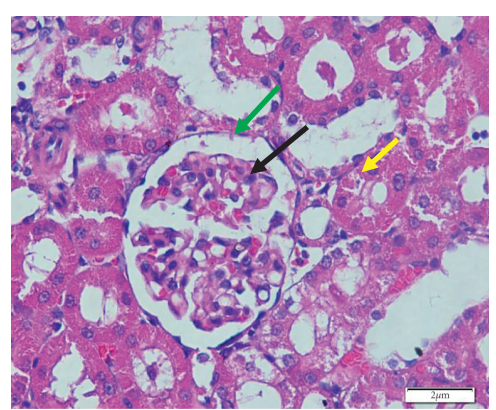

(e)

Figure 6: Histopathology of the kidney in (a) the normal control group; (b) the diabetic control group; (c) diabetic rats treated with $250 \mathrm{mg} /$ $\mathrm{kg}$ extracts; (d) diabetic rats treated with $500 \mathrm{mg} / \mathrm{kg}$ extracts; and (e) diabetic rats treated with metformin $200 \mathrm{mg} / \mathrm{kg}$, with $600 \times \mathrm{mag}$ nification. Black arrows show glomerulus; yellow arrows show proximal tubules; and green arrows show Bowman's space.

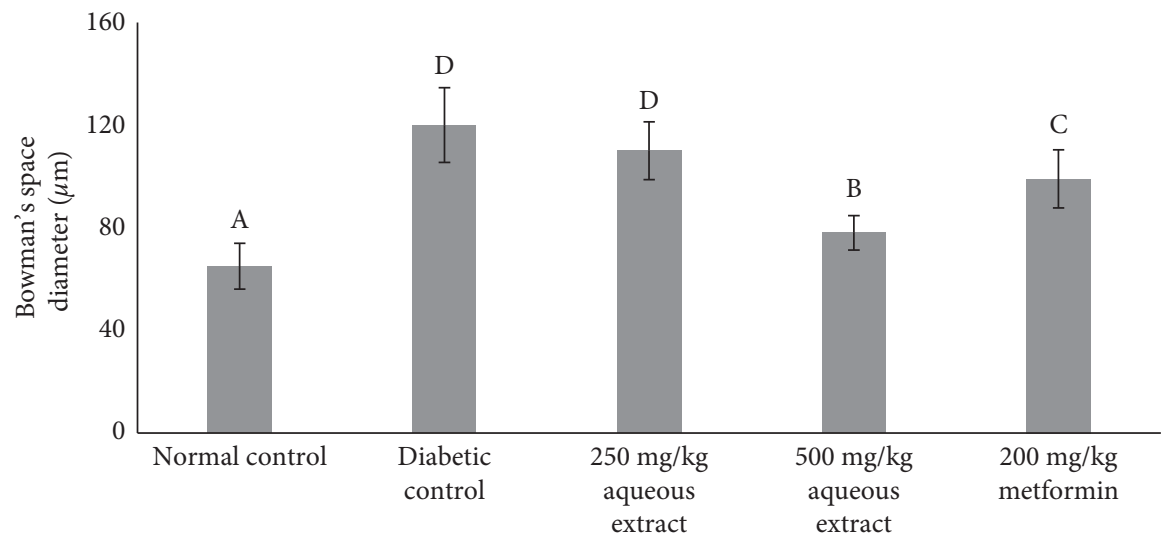

FIGURE 7: Bowman's space diameter for all groups. Different notations indicate significant differences between treatments $(p<0.05)$.

number of free radicals existing in diabetic groups. These were shown in STZ-induced diabetic rats that demonstrated highly significant hyperglycemia as compared to control healthy rats. The increase in the blood glucose and MDA levels in serum was up to $299 \%$ and $448 \%$, respectively. Oxidative stress produced by the hyperglycemic state weakens the antioxidant defense mechanism of the body and, consequently, surges MDA levels [15]. Malondialdehyde is a product of polyunsaturated fatty acid peroxidation in cells [31]. A surge in free radicals leads to excess production of MDA. The malondialdehyde level is generally identified as an oxidative stress marker and the antioxidant status in the diabetic state [32].

It is probable that it was unable to reverse back the number of antioxidants derived from aqueous extracts to cell homeostasis or completely repair cell damages that occurred. The metformin-treated group (group 5) also showed a substantial reduction in their blood glucose and MDA levels. Nonetheless, their decreases did not successfully reverse back blood glucose and MDA concentrations to normal conditions in the same way as in the normal control group (group 1).

Similar trends were also shown in the histopathological alterations in the diabetic rats' organs. Treatment with the aqueous root extracts of $R$. tuberosa $\mathrm{L}$. at a $250 \mathrm{mg} / \mathrm{kg}$ dose cannot restore pathological changes of the pancreas to a healthy level, while a $500 \mathrm{mg} / \mathrm{kg}$ dose showed a moderate restoration to the healthy condition. Although, the Langerhans islet diameter was significantly elevated in the treated rats in the $500 \mathrm{mg} / \mathrm{kg}$ dose compared to that of the diabetic 
group. The observed nephroprotective effects of the aqueous root extracts in terms of normalizing the glomerular size, the number of proximal tubular cells, and Bowman's space diameter were also shown in the treatment with the highest dose $(500 \mathrm{mg} / \mathrm{kg})$. Nonetheless, histopathological examination of the liver revealed a significant number of repair changes in treated diabetic animals compared to the untreated ones, from the treatment dose of $250 \mathrm{mg} / \mathrm{kg}$. This was shown in the significant decline in the vacuolization degrees.

Treatments with aqueous root extracts significantly improve pathological changes of the pancreas, liver, and kidney most probably due to their high flavonoid and phenolic content. Polyphenol compounds are suggested to have significant effects on the regulation of oxidative stress through a number of mechanisms. These include reducing inflammation through inactivation of mitogen-activated protein kinase (MAPK) signalling pathways [33], repairing DNA damages caused by oxidative stress via the nuclear factor erythroid 2-related factor 2 (Nrf2) pathway [34], and decreasing apoptosis through regulating protein kinase $\mathrm{B}$ (AKT)/caspase expression [35].

We believe that this is the first study on the in vivo pharmacological evaluation of this antidiabetic effect of the aqueous root extracts of $R$. tuberosa $\mathrm{L}$. Yet, it is suggested that a higher dose of treatments, more than $500 \mathrm{mg} / \mathrm{kg}$, can be applied to achieve more prominent effects. Besides, the root extracts of $R$. tuberosa L. can also be extracted with water with an addition of acid to attract more secondary metabolites.

\section{Conclusions}

In conclusion, our current study has established that the aqueous root extracts of $R$. tuberosa $\mathrm{L}$. could be considered to be used as antidiabetic drugs. The antihyperglycemic activity is suggested from the significant reduction in blood glucose levels, MDA serum levels, and pancreatic levels after medium-term administration of the aqueous root extracts of $R$. tuberosa L. Additionally, the aqueous root extracts of $R$. tuberosa $\mathrm{L}$. have shown a crucial preventive effect against pancreas, renal fibrosis, and liver complications. Nevertheless, a higher dose of aqueous extracts is suggested to attain more substantial outcomes.

\section{Data Availability}

The data used to support this study are included in the article and will be made available on request.

\section{Conflicts of Interest}

The authors declare no conflicts of interest regarding the publication of this paper.

\section{Acknowledgments}

This study was supported by the HPU grant, Brawijaya University, year 2021, with the contract no. 537.10.2/ UN10.C10/PN/2021.

\section{References}

[1] P. Z. Zimmet, "Diabetes and its drivers: the largest epidemic in human history?" Clinical Diabetes and Endocrinology, vol. 3, no. 1, pp. 1-8, 2017.

[2] W. Kerner and J. Brückel, "Definition, classification and diagnosis of diabetes mellitus," Experimental and Clinical Endocrinology \& Diabetes, vol. 122, no. 07, pp. 384-386, 2014.

[3] P. Zimmet, K. G. Alberti, D. J. Magliano, and P. H. Bennett, "Diabetes mellitus statistics on prevalence and mortality: facts and fallacies," Nature Reviews Endocrinology, vol. 12, no. 10, pp. 616-622, 2016.

[4] A. Pranoto and D. Purnamasari, "Guidelines on the management and prevention of prediabetes," Acta Medica Indones - Indones J Intern Med.vol. 46, no. 4, pp. 348-359, 2014.

[5] E. W. Gregg, N. Sattar, and M. K. Ali, "The changing face of diabetes complications," The Lancet Diabetes \& Endocrinology, vol. 4, no. 6, pp. 537-547, 2016.

[6] D. L. Chothani, M. Patel, S. Mishra, and H. Vaghasiya, "Review on Ruellia tuberosa (cracker plant)," Pharmacognosy Journal, vol. 2, no. 12, pp. 506-512, 2010.

[7] K. Afzal, M. Uzair, B. A. Chaudhary, A. Ahmad, S. Afzal, and M. Saadullah, "Genus Ruellia: pharmacological and phytochemical importance in ethnopharmacology," Acta Poloniae Pharmaceutica, vol. 72, no. 5, pp. 821-827, 2015.

[8] M. N. Samy, S. Sugimoto, K. Matsunami, H. Otsuka, and M. S. Kamel, "Chemical constituents and biological activities of genus Ruellia," International Journal of Pharmacognosy, vol. 2, no. 6, pp. 270-279, 2015.

[9] J.-H. Xu, Y. M. Lo, W.-C. Chang et al., "Identification of bioactive components from Ruellia tuberosa L. On improving glucose uptake in TNF- $\alpha$-induced insulin-resistant mouse FL83B hepatocytes," Evidence-based Complementary and Alternative Medicine, vol. 2020, pp. 1-7, 2020.

[10] A. Safitri, A. Srihardyastutie, A. Srihardyastutie, A. Roosdiana, A. a. Aulanni'am, and E. N. L. Octaviana, "Effects of root extract of Ruellia tuberosa L. On kidneys of diabetic rats," Journal of Mathematical and Fundamental Sciences, vol. 51, no. 2, pp. 127-137, 2019.

[11] A. Safitri, Sutrisno, A. Roosdiana, and C. A. Evindasari, "Hypoglycaemic activity of hydroethanolic root extracts of Ruellia tuberosa L in diabetic rats," Journal of Physics: Conference Series, vol. 1146, Article ID 012020, 2019.

[12] A. Roosdiana, Sutrisno, C. Mahdi, and A. Safitri, "The influence of ethanolic root extracts of Ruellia tuberosa L. On pancreatic protease activity and MDA level of rats (Rattus norvegicus) induced by MLD-STZ," IOP Conference Series: Earth and Environmental Science, vol. 217, Article ID 012041, 2019.

[13] A. Safitri, A. Roosdiana, N. Arrochmah, and S. S. Nur'Adya, "Anti-diabetic properties of root extracts of Ruellia tuberosa L: effects on serum enzyme activity," Journal of Physics: Conference Series, vol. 1374, Article ID 012030, 2019.

[14] S. Vasantharaj, S. Sathiyavimal, P. Senthilkumar, F. LewisOscar, and A. Pugazhendhi, "Biosynthesis of iron oxide nanoparticles using leaf extract of Ruellia tuberosa: antimicrobial properties and their applications in photocatalytic degradation," Journal of Photochemistry and Photobiology B: Biology, vol. 192, pp. 74-82, 2019.

[15] A. Roosdiana, F. S. Permata, R. I. Fitriani, K. Umam, and A. Safitri, "Ruellia tuberosa L. Extract improves histopathology and lowers malondialdehyde levels and TNF alpha expression in the kidney of streptozotocin-induced diabetic rats," Veterinary Medicine International, vol. 2020, pp. 1-7, 2020. 
[16] A. Ahangarpour, H. Heidari, M. S. Junghani, R. Absari, M. Khoogar, and E. Ghaedi, "Effects of hydroalcoholic extract of Rhus coriaria seed on glucose and insulin related biomarkers, lipid profile, and hepatic enzymes in nicotinamidestreptozotocin-induced type II diabetic male mice," Research in pharmaceutical sciences, vol. 12, no. 5, pp. 416-424, 2017.

[17] A. Safitri, F. Fatchiyah, D. R. T. Sari, and A. Roosdiana, "Phytochemical screening, in vitro anti-oxidant activity, and in silico anti-diabetic activity of aqueous extracts of Ruellia tuberosa L," Journal of Applied Pharmaceutical Science, vol. 10, no. 3, pp. 101-108, 2020.

[18] V. L. Singleton and J. A. Rossi, "Colorimetry of total phenolics with phosphomolybdicphosphotungstic acid reagents," American Journal of Enology and Viticulture, vol. 16, pp. 144-158, 1965.

[19] K. Kartini, L. Arifa Dwi Putri, and H. Mochammad Arbi, "FTIR-based fingerprinting and discriminant analysis of Apium graveolens from different locations," Journal of Applied Pharmaceutical Science, vol. 10, no. 12, pp. 62-67, 2020.

[20] O. F. Fagbohun, P. O. Awoniran, O. O. Babalola, F. K. Agboola, and T. A. M. Msagati, "Changes in the biochemical, hematological and histopathological parameters in STZ-Induced diabetic rats and the ameliorative effect of Kigelia africana fruit extract," Heliyon, vol. 6, no. 5, Article ID e03989, 2020.

[21] M. Slaoui and L. Fiette, "Histopathology procedures: from tissue sampling toHistopathological evaluation," Methods in Molecular Biology (Methods and Protocols, vol. 691, 2011.

[22] V. N. G. Yajarla, R. P. Nimmanapalli, S. Parikapandla, G. Gupta, and R. Karnati, "Anti-inflammatory and antiproliferative properties ofChromolaena odorataLeaf extracts in normal and skin-cancer cell lines," Journal of Herbs, Spices, \& Medicinal Plants, vol. 20, no. 4, pp. 359-371, 2014.

[23] S. Hemadri Reddy, A. S. Al-Rawahi, and A. S. Al-Kalbani, "Hypoglycemic effect of black cumin (nigella sativa) seed and Senna alexandria (Cassia angustifolia) leaf extracts on alloxaninduced mice," Journal of Herbs, Spices, \& Medicinal Plants, vol. 23, no. 4, pp. 401-408, 2017.

[24] T. K. Bera, K. Chatterjee, and D. Ghosh, "Remedial hypoglycemic activity of n-hexane fraction of hydro-methanol extract of seed ofSwietenia mahagoni(L.) jacq. In streptozotocin-induced diabetic rat: a comparative evaluation," Journal of Herbs, Spices, \& Medicinal Plants, vol. 21, no. 1, pp. 38-58, 2015.

[25] S. S. Gurav, N. S. Gurav, A. T. Patil, and N. J. Duragkar, "Effect of explant source, culture media, and growth regulators on callogenesis and expression of secondary metabolites of curcuma longa," Journal of Herbs, Spices, \& Medicinal Plants, vol. 26, no. 2, pp. 172-190, 2020.

[26] M. Jalili-Nik, M. Soukhtanloo, S. Javanshir et al., "Effects of ethanolic extract of Ferula gummosa oleo-resin in a rat model of streptozotocin-induced diabetes," Research in Pharmaceutical Sciences, vol. 14, no. 2, pp. 138-145, 2019.

[27] S. Eghbaliferiz and M. Iranshahi, "Prooxidant activity of polyphenols, flavonoids, anthocyanins and carotenoids: updated review of mechanisms and catalyzing metals," Phytotherapy Research, vol. 30, no. 9, pp. 1379-1391, 2016.

[28] Y. Wang, A. Wang, H. Alkhalidy et al., "Flavone hispidulin stimulates glucagon-like peptide- 1 secretion and ameliorates hyperglycemia in streptozotocin-induced diabetic mice," Molecular Nutrition \& Food Research, vol. 64, no. 6, Article ID 1900978, 2020.

[29] D. Das, S. Sarkar, J. Bordoloi, S. B. Wann, J. Kalita, and P. Manna, "Daidzein, its effects on impaired glucose and lipid metabolism and vascular inflammation associated with type 2 diabetes," BioFactors, vol. 44, no. 5, pp. 407-417, 2018.

[30] R. Heidari, H. Niknahad, A. Sadeghi et al., "Betaine treatment protects liver through regulating mitochondrial function and counteracting oxidative stress in acute and chronic animal models of hepatic injury," Biomedicine \& Pharmacotherapy, vol. 103, pp. 75-86, 2018.

[31] O. M. Ighodaro, "Molecular pathways associated with oxidative stress in diabetes mellitus," Biomedicine \& Pharmacotherapy, vol. 108, pp. 656-662, 2018.

[32] K. Smriti, K. M. Pai, V. Ravindranath, and K. C. Pentapati, "Role of salivary malondialdehyde in assessment of oxidative stress among diabetics," Journal of Oral Biology and Craniofacial Research, vol. 6, no. 1, pp. 42-45, 2016.

[33] K. V. Doan, C. M. Ko, A. W. Kinyua et al., "Gallic acid regulates body weight and glucose homeostasis through AMPK activation," Endocrinology, vol. 156, no. 1, pp. 157-168, 2015.

[34] V. Prajitha and J. E. Thoppil, "Genotoxic and antigenotoxic potential of the aqueous leaf extracts of Amaranthus spinosus Linn. using Allium cepa assay," South African Journal of Botany, vol. 102, pp. 18-25, 2016.

[35] S. Li, H. Y. Tan, N. Wang, F. Cheung, M. Hong, and Y. Feng, "The potential and action mechanism of polyphenols in the treatment of liver diseases," Oxidative Medicine and Cellular Longevity, vol. 2018, pp. 1-25, 2018. 